\title{
Reflexões sobre a territorialização LGBT na luta pela terra no Brasil
}

\author{
Reflections of LGBT territorialization at the conflict for land in Brazil \\ Reflexiones sobre la territorialización LGBT en la lucha por la tierra en Brasil
}

\author{
Marcelo Cervo Chelotti ${ }^{1}$ \\ Samuel Lucas Silva Gomes Santos ${ }^{2}$ \\ Vinícius Nunes Fileto ${ }^{3}$
}

\begin{abstract}
RESUMO: A Jornada Universitária pela Reforma Agrária (JURA) da Universidade Federal de Uberlândia acontece tradicionalmente através de uma agenda nacional de eventos com esse fim. A intenção deste texto é trazer as reflexões sobre a territorialização do movimento de lésbicas, gays, bissexuais, travestis e transexuais (LGBT) dentro dos movimentos de luta pela terra no Brasil, especialmente os ligados à Via Campesina, tratados em uma roda de conversa promovida por estudantes do tema para os alunos e integrantes dos movimentos sociais da JURA-UFU. Entendendo que a inserção dessa pauta é um processo que está ocorrendo em escala nacional, o objetivo da roda é levantar questões que são recorrentemente invisibilizadas como a pauta das sexualidades camponesas e a vivência LGBT dentro de acampamentos e assentamentos da Reforma Agrária no Brasil.
\end{abstract}

Palavras-chave: Luta pela terra. Reforma Agrária. Movimentos sociais. LGBT.

\begin{abstract}
The University Journey for Agrarian Reform (JURA) at the Federal University of Uberlândia takes place traditionally through a national agenda of events for this purpose. The intention of this text is to reflect the territorialization of the Lesbian, Gay, Bisexual, Transvestite and Transsexual movement within the land conflict's movements at Brazil, especially those linked to Via Campesina. A conversation circle was promoted by the researchers at the 5th University Conference in Defense of Agrarian Reform at UFU. The insertion of this agenda is a process that is taking place on a national scale. The circle raised issues that are often made invisible, such as the agenda of peasant sexualities and the LGBT experience within land reform camps and settlements in Brazil.
\end{abstract}

Keywords: Conflicts for land. Land reform. Social movements. LGBT.

RESUMEN: La Jornada Universitaria para la Reforma Agraria de la Universidad Federal de Uberlândia (JURA-UFU) se realiza tradicionalmente a través de una agenda nacional de eventos con este fin. La intención del texto es traer reflexiones sobre la territorialización del movimiento de Lesbianas, Gays, Bisexuales, Travestis y Transgénero (LGBT) dentro de los movimientos de lucha por la tierra en Brasil, especialmente aquellos vinculados a la Vía

1 Doutor em Geografia pela Universidade Federal de Uberlândia, Minas Gerais, Brasil, com estágio de doutoramento na Universidade de Buenos Aires, Argentina; estágio pós-doutoral na Universidade Federal do Rio Grande do Sul, Brasil; professor associado do Instituto de Geografia da Universidade Federal de Uberlândia, Minas Gerais, Brasil; coordenador do Laboratório de Geografia Agrária (LAGEA/UFU), membro do Núcleo de Estudos Agrários e Territoriais (NEAT) (mcervochelotti@gmail.com).

2 Graduando em Geografia na Universidade Federal de Uberlândia, Minas Gerais, Brasil (samuellucasg14@gmail.com).

${ }^{3}$ Mestre em Geografia na Universidade Federal de Uberlândia, Minas Gerais, Brasil; bolsista CAPES; membro do Laboratório de Geografia Agrária (LAGEA) e do Núcleo de Estudos Agrários e Territoriais (NEAT) (viniciusfileto2@gmail.com). 
Campesina tratados en una conversación promovida por los estudiantes de la tematica en la Universidad para estudiantes y para miembros de movimientos sociales que participan de JURA-UFU. Entendiendo que la inserción de esta agenda es un proceso que se está llevando a cabo a escala nacional, el propósito de la ronda es plantear temas que son recurrentemente invisibles como la agenda de las sexualidades campesinas y la experiencia LGBT dentro de los campamentos y asentamientos de reforma agraria en Brasil.

Palabras clave: Lucha por la tierra. Reforma Agraria. Movimientos Sociales. LGBT.

\section{INTRODUÇÃO}

Este texto tem por finalidade trazer as reflexões decorrentes da roda de conversa intitulada “Territorialização LGBT na luta pela terra no Brasil” da V Jornada Universitária pela Reforma Agrária (JURA), ocorrida em maio/2019, na Universidade Federal de Uberlândia (UFU), e vem como uma contribuição para a expansão do movimento das LGBT Sem Terra que vivencia contexto de ascensão no Brasil.

A motivação da produção do espaço da roda que tem por fim este texto vem de uma pesquisa de mestrado acadêmico desenvolvida no Programa de Pós-Graduação em Geografia (PPGEOUFU). Na pesquisa em questão, intitulada "Levantando a bandeira colorida na luta pela terra: territorialidades e espacialidades LGBT nos movimentos socioterritoriais do campo no Brasil", vamos nos debruçar em compreender geograficamente como os movimentos sociais da luta pela terra e LGBT se encontram, nos preocupando especificamente com a interseção desses dois movimentos marcada no Brasil pela criação do coletivo e grupo de estudos LGBT Sem Terra no Movimento dos Trabalhadores Rurais Sem Terra (MST).

Essa temática permeia nossa experiência acadêmica desde o final de 2016, quando aprovados no Programa de Bolsa de Iniciação Científica (PIBIC) pela Fundação de Amparo à Pesquisa de Minas Gerais (FAPEMIG). Desde então, nosso enfoque recaiu na coleta de textos jornalísticos publicados pelo MST em relação à temática das LGBT e da diversidade sexual, e reflexão teórica sobre a temática. Com resultados humildes e inconclusos perante a riqueza do material até então, trouxemos o debate para o mestrado.

No mestrado, muito foi desenvolvido e, sobretudo, refletido. Na defesa, com as colocações da banca, percebemos que muito havia para ser amadurecido e que o tema tem uma profundidade considerável a ser explorada. A partir daí, buscamos novas perspectivas de compreender a temática em múltiplas facetas. Estamos alicerçados pela Geografia, e temos o compromisso 
com tal ciência, entretanto mediamos isso com a nossa concepção de que a interdisciplinaridade é uma prática interessante para a pesquisa.

Nesse sentido, divulgamos a pesquisa por meio da roda de conversa, modalidade da V JURA, que para nós teve resultados extremamente positivos. Ver pessoas dos movimentos sociais que não sabiam da existência do coletivo e das movimentações LGBT Sem Terra e ver pessoas que sabiam e se conscientizaram sobre a complexidade da territorialização LGBT na luta pela terra tornaram esse momento único para a continuidade no andamento da pesquisa e para a troca de experiências.

\section{Percurso histórico da luta pela terra no Brasil: da questão agrária à questão de gênero e sexualidade}

A posse da terra no Brasil está relacionada diretamente com o poder do proprietário. Para além do poder econômico, tem também o poder político de ser proprietário da terra. Quanto maior a fazenda, mais poder envolvido. $\mathrm{O}$ acesso à terra no Brasil se tornou, no século $\mathrm{XX}$, um grande embate, a partir das raízes concentradoras da estrutura fundiária e das contradições evidenciadas pela iniquidade do acesso à terra.

Como afirma Stédile (2005), o Brasil optou por um modelo de industrialização dependente. Aqui o modo de produção capitalista está em franca expansão, especialmente o estrangeiro. Esse processo se estendeu especialmente entre os anos de 1950 e 1960, momento em que as decisões sobre a política econômica governamental foram tomadas em função dos interesses e das perspectivas abertas à burguesia industrial, em sentido lato (IANNI, 2005). Isso significou muito para os caminhos tomados para o desenvolvimento rural. É a formação do capital industrial e seu desenvolvimento, que vai sobressair à vida urbana perante a vida rural.

O desenvolvimento do capitalismo moderno no campo acompanha processos bastante importantes de serem entendidos no sentido de desvendar a tão conflituosa questão agrária no Brasil. Esse processo, como afirma Porto Gonçalves (1997), tinha o intuito de modernizar a agricultura tanto do modo de vista tecnológico como das relações sociais. A modernização das relações sociais estava muito ligada em reforçar a proposta de que a cidade é o espaço de reprodução da vida moderna e que o campo é o espaço de produção de matéria prima para a indústria. Isso converge diretamente com a proposição do fim processual do fim do campesinato. 
É aqui que problematizamos o processo conhecido como êxodo rural, “estimulado pela lógica do capitalismo, para que os filhos dos camponeses - em vez de sonharem com sua reprodução como camponeses - em vez de lutarem pela terra, pela reforma agrária - se iludissem com novos empregos e salários na indústria.” (STEDILE, 2005, p. 31). Uma ideologia produzida pelo grande capital, como estratégia para enfraquecimento da reprodução da vida camponesa.

Os movimentos pela reforma agrária no Brasil são historicamente influenciados pela ideologia comunista e pelos movimentos pela reforma agrária na América Latina, sobretudo os vencedores, como no caso de Cuba e México (VEIGA, 1984). Exemplo disso é a influência do Partido Comunista Brasileiro (PCB) no fomento à germinação das movimentações dos trabalhadores rurais, fundamentadas na luta de classes e no combate à lógica burguesa da acumulação capitalista, que emergia consideravelmente na primeira metade do século XX, constituindo os primeiros embates entre a classe dominante e a classe das massas exploradas do campo (MEDEIROS, 1989).

Nesse momento, como afirma Medeiros (1989), é revivido o conceito de campesinato, que se faz necessário para duas coisas: englobar a diversidade identitária que se configura o campo brasileiro e o classificar homogeneamente através da perspectiva da contracorrente ao desenvolvimento do capitalismo agrário no território brasileiro. É a partir dessa categoria, que o PCB vai tentar forjar a bandeira da reforma agrária, que lhe daria um sentido histórico.

É perceptível que a espacialização histórica dos movimentos pela reforma agrária no Brasil indica cada vez mais para uma identidade autônoma. Na entrada para década de 1960, a partir dos posicionamentos marcados no Congresso Camponês, em 1961, o real distanciamento da proposta do PCB ante a proposta dos movimentos autônomos pela reforma agrária é referente à intensidade e radicalidade. Enquanto um enxergava a necessidade de medidas mais cautelosas, o outro imprimia a defesa pela reestruturação fundiária. Este segundo é que viria a se encontrar na identidade da luta pela terra.

A Igreja nesse contexto é importante constar. O papel político e de organização protagonizado naquele momento pelos movimentos estudantis com vínculo cristão eram expressivos, como a Juventude Agrária Católica (JAC) e a Juventude Operária Católica (JOC) (GOHN, 2001). Tais movimentos objetivavam direcionar as lutas para as necessidades gerais das massas. Nessa perspectiva, se voltaram para o trabalho de sindicalização rural, tendo por horizonte a construção de uma nova sociedade, de perfil socialista. 
Com o Golpe Militar de 1964, tornou-se impossível promover ações reivindicatórias para desapropriação de terras (SIGAUD, 2009). No entanto, a primeira ocupação vitoriosa, desdobrando-se na desapropriação, ocorreu antes do fim do Governo Militar na fazenda Macali, no município de Ronda Alta, no Rio Grande do Sul, em 7 de setembro de 1979 (LOERA, 2009). Isso nos força a acreditar que a redemocratização do Brasil foi um processo. Começou antes da queda do Governo Militar, em 1985, e foi um processo ainda violento. "Para entender que o processo de redemocratização houve intensos conflitos [...] basta considerar que, entre 1980 e 1981, houve 197 mortos e 518 feridos na luta pela terra" (MARTINS, 1985, p. 91).

Nesse processo de resistência e luta, foi determinante a ação dos agentes de mediação contrários à ideologia do Estado, que passam a se organizar, já prevendo o fim do Governo Militar. No começo dos anos 1980, começa a se articular, no Rio Grande do Sul, uma ação coordenada de ocupação de terras ociosas por parte de trabalhadores autodenominados Sem Terra. A organização de ocupações que vão se espalhar por todo o Brasil vai dar origem ao Movimento dos Trabalhadores Rurais Sem Terra (MST) (PINTO, 1995). Percebe-se a formação da identidade da luta pela terra que germina o movimento, organizado coletivamente e por um objetivo comum. Os movimentos são expressões de contradições não resolvidas e de interesses sociais não atendidos (GRZYBOWSKI, 2004). Os interesses sociais não atendidos seriam o cumprimento da função social da terra e a efetivação da reforma agrária revolucionária que resolveria o problema de acesso à terra. As expressões do MST eram reivindicatórias e materializadas na formação de acampamentos.

A Confederação Nacional dos Trabalhadores na Agricultura (CONTAG) é criada em janeiro de 1964. Com o Golpe Militar ela sofreu grande repressão. Entretanto, como afirma Veiga (1984), em 1968 há uma relativa rearticulação dos movimentos populares expressivamente representados pelos sindicatos e a CONTAG, que faz diversos congressos definindo os caminhos da reforma agrária (VEIGA, 1984). A CONTAG lutava pela terra com particularidades mais voltadas para o assalariado rural.

Tanto a CONTAG quanto o MST enxergavam a necessidade da reforma agrária. Até o Banco Mundial tinha um projeto. Entretanto todos seguiam por caminhos diferentes. O projeto político das grandes empresas ligadas ao Banco Mundial se fundava na industrialização total do campo, reduzindo a participação do camponês no processo produtivo do pacote tecnológico. Projetos políticos da CONTAG e do MST se aproximavam pelas demandas 
voltadas para a classe trabalhadora rural, entretanto, a CONTAG, em específico, defendia maiores direitos aos assalariados rurais e melhores condições de vida, e o MST, para além, defendia uma reestruturação fundiária fundada na concepção de terra para quem nela trabalha, a reforma agrária popular revolucionária. Nesse sentido, ambas se distinguem em suas respectivas profundidades (GERMER, 2004).

A luta pela terra no Brasil se mostra ainda latente, haja vista a inconclusa reforma agrária e a questão agrária que ainda assombra o rural brasileiro. Temporalmente, é notório que a organização dos movimentos de luta pela terra vai se (re)estruturando e inserindo demandas apontadas pelos sujeitos que constroem esse processo. No embate entre as forças políticas, novos e antigos sujeitos têm incorporado em suas lutas novos conteúdos e novas propostas em suas estratégias (PACHECO, 2004).

A complexidade que alcançou a luta pela terra no Brasil chamou atenção dos movimentos sociais para sua estrutura. Era preciso articulações mais profundas que demandavam dinâmicas multidimensionais. A preocupação na atuação da luta pela terra se torna então global, nacional, regional e local.

No MST, as suas articulações se desdobraram em transformações na sua estrutura organizativa. Sua estruturação consiste em três partes interativas: (1) as instâncias de representação; (2) os setores de atividades; e (3) as organizações com registro público. (FERNANDES, 2009). Nesse sentido, tomaremos uma dessas três partes como frente, no caso a segunda, os setores de atividades, para tentar entender, de maneira mais específica a estrutura do MST enquanto movimento social plural e transversal da maneira que ele se propõe.

Fernandes (2006, p. 3), identificando o processo entre 1979 a 1985, como fase embrionária do MST, afirma que já estava imbricada a criação de setores e comissões que "definiram o modelo de sua estrutura organizativa". No século XXI, a parte dos setores de atividades demonstra a imensidão que é o MST enquanto movimento social, sendo composto por três secretarias (Nacional; Estadual; Regional), dez setores (Frente de Massa; Formação; Educação; Produção, Cooperação e Meio ambiente; Comunicação; Finanças; Projetos; Direitos Humanos; Saúde; Gênero), e três coletivos (Relações internacionais; Cultura; Mística). É essa parte que o conduz enquanto articulação social a dialogar com as diferentes 
demandas existentes no MST, que acredita ser importante para o fortalecimento da luta pela terra e do sujeito da luta pela terra.

Os movimentos da luta pela terra no Brasil entram no século XXI inserindo em suas agendas qualidade de vida, soberania alimentar e direitos humanos. A Via campesina, além de ser uma entidade autônoma no Brasil, media a internacionalização da luta de alguns movimentos no Brasil. Esses movimentos são complexos, fundamentam sua continuidade na militância e trabalho de base, se estruturam em setores e vão sempre para além da simples reivindicação do lote.

As reivindicações dos movimentos comparecem de forma complexa para ganhar mais legitimidade e dar continuidade à sua luta. São as mais variadas reivindicações que constituem a agenda dos movimentos. No sentido em que caminha a pesquisa, chamamos a atenção para o que trata a política de respeito aos direitos humanos. Entendemos que ter essa preocupação na sua pauta política foi o que desencadeou a mobilização de grupos sociais historicamente marginalizados, a exemplo disso as mulheres e as pessoas LGBT.

O MST é o movimento de luta pela terra que inaugura o debate sobre gênero na sua estrutura organizativa. Segundo Mariano e Paz (2018), desde seu início, o MST buscou a integração familiar. A partir daí deu abertura para questionamentos, haja vista as contradições apontadas na estrutura familiar camponesa. Para esses autores, as mulheres foram as primeiras a questionar a organização quanto aos mecanismos para realmente assegurar a participação de todos os integrantes da família. Ele se insere inicialmente em suas Comissões Políticas, em 1995, que "atuam em relação a cinco eixos temáticos: Soberania Alimentar e Comércio Internacional; Reforma Agrária e Desenvolvimento Rural; Gênero e Direitos Humanos; Agricultura Camponesa Sustentável; Biodiversidade e Recursos Genéticos” (FERNANDES, 2009, p. 186). A organização das mulheres do MST na década de 1990 é concomitante ao crescimento de famílias em acampamentos de terra no Brasil.

As mulheres da Via Campesina vinham se organizando desde 1996. Nesse momento, o MST já fazia parte da organização. "Ao consolidar o movimento internacional, a questão do papel das mulheres e da igualdade de gênero apareceu rápida e espontaneamente" (VIEIRA, 2008, p. 154). Alinhada à luta do MST, a Via Campesina vem criando uma identidade do movimento, como forma de juntar a diversidade de movimentos camponeses, de diversas regiões em um só movimento, materializado na Via Campesina. 
Como aludido anteriormente, a Via Campesina articula diversos movimentos em ações, reivindicações e propostas, ultrapassando as fronteiras nacionais, territórios e escalas (RIBEIRO, 2015). Atualmente, a Via Campesina "se desafia a formular propostas em relação aos seguintes temas: reforma agrária, biodiversidade e recursos genéticos, soberania alimentar, direitos humanos, agricultura camponesa sustentável, migração e trabalhadores rurais, questão de gênero" (VIEIRA, 2008, p. 154). E espacializa isso a partir de suas ações reivindicatórias e dos movimentos ligados a tal organização.

Paz e Mariano (2018) inovam nos estudos sobre os movimentos da luta pela terra chamando a atenção para a inserção do debate da diversidade sexual no MST. Para esses autores, "o MST é um movimento popular que organiza sujeitos expostos a grandes contradições da sociedade capitalista, patriarcal e racista" (MARIANO; PAZ, 2018, p. 294). Na história do MST identificam-se muitas militantes e dirigentes LGBT com trajetórias perpassadas por conquistas, mas também por preconceitos e discriminações (MARIANO; PAZ, 2018). Esses processos são conflituosos e geram territorialidades progressistas e a favor da diversidade, bem como emergem territorialidades conservadoras e patriarcais frente ao processo de inserção do debate na estrutura organizativa do Movimento.

A organização das LGBT Sem Terra foi muito influenciada pela Comissão Política de Gênero que, ao pautar as contradições da estrutura familiar e problematizar a tradição patriarcal do movimento possibilita a reprodução das LGBT Sem Terra (MARIANO; PAZ, 2018). Nesse sentido, construindo territorialidades nas entranhas desses movimentos, torna-se latente a abordagem socioterritorial e emerge a consciência de que se pode ter LGBT na luta pela terra, e que sua presença é relevante na resistência necessária para territorialização dos movimentos frente ao capitalismo globalizado no campo Brasileiro.

A organização política das LGBT Sem Terra se inicia no contexto dos movimentos socioterritoriais do campo no Brasil, em 2014, com uma roda de conversas sobre diversidade sexual no MST do Ceará, expandindo a ação para outros estados. Já no ano de 2015, foi organizada, através da juventude do MST da Bahia, uma agitação e propaganda anti homofobia durante a marcha estadual (MARIANO; PAZ, 2018). Neste mesmo ano, no dia do orgulho LGBT, 28 de junho, foi a vez da Escola Nacional Florestan Fernandes (ENFF) "acolher uma ação da militância LGBT Sem Terra. Uma roda de conversa com estudantes vindos de diversos países da América Latina e de várias organizações populares do Brasil" (MARIANO; PAZ, 2018, p. 298Com todas essas movimentações, as LGBT Sem Terra já se 
espacializam dentro do movimento. Entretanto a grande marca da auto-organização das LGBT Sem Terra e formação da identidade LGBT Sem Terra é o Seminário "O MST e a Diversidade Sexual" que reuniu 35 militantes de 13 estados do Brasil (MARIANO; PAZ, 2018). O grupo de estudos sobre diversidade sexual foi criado e a formação política das militantes LGBT Sem Terra era parte integrante da auto-organização, além da reivindicação para a adoção da liberdade sexual como pauta integrante do MST.

A resistência das pessoas LGBT no MST é explicitada no texto do Caderno de Formação 5. Ao contextualizar a criação dos espaços de auto-organização no MST afirma que "muito antes desses espaços surgirem, os mesmos sujeitos já se encontravam contribuindo em algumas instâncias, o que não acontece sem uma história de enfrentamento a fatores conservadores" (MST, 2017, p. 7).

Há muitas pessoas LGBT que vivem no campo brasileiro, e também na luta pela terra, mas diversos fatores socioespaciais as fazem se desmobilizar. Para a pesquisa, o enfoque é dado para as pessoas que partiram para o enfrentamento e construíram a identidade LGBT Sem Terra, condicionada também por apoio de forças externas.

A ação de atores externos na produção do espaço também condiciona as relações de poder e de negociação de espaços. Em 2014, o MST junto ao movimento LGBT participou da marcha contra a homofobia em Brasília. No mesmo ano, no VI Congresso do MST, algumas questões referentes a esse tema foram suscitadas a partir da demarcação dos espaços por elas, como a matéria veiculada sobre as pessoas trans. Houve também espaços de formação que possibilitaram a expansão do debate para além da dimensão política, atingindo a dimensão cotidiana, que é controversa e paradoxal (MST, 2017). Em 2016, foram alteradas as normas gerais do MST para incluir e reconhecer as pessoas LGBT, também como parte da organização, como é possível observar no quadro 1. 
Quadro 1 - Modificações das normas gerais no MST com o reconhecimento das LGBT Sem Terra (2017)

1.3 Natureza do MST: participam no Movimento, sem distinção de idade, orientação sexual ou identidade de gênero, todos os membros da família: homens, mulheres, idosos, jovens e crianças.

3.6 Educação e Cultura: os membros devem combater, permanentemente, todas as formas de preconceito social, para que não ocorra a discriminação de gênero, idade, etnia, religião, identidade de gênero e orientação sexual, etc.

3.7 Direitos Sociais combater todas as formas de violência contra as mulheres, crianças e LGBT (Lésbicas, Gays, Bissexuais, Transexuais e Travestis), penalizando exemplarmente seus praticantes.

Fonte: MST (2017).

Todas essas movimentações só se dão com a justificativa da exclusão histórica das pessoas LGBT do campo brasileiro. O MST vai incluir essa pauta no século XXI, em 2013, formalmente, e em 2016, no reconhecimento em suas normas gerais (MST, 2017). Relações expressas por forças hegemônicas vinculadas ao patriarcado e ao capitalismo. A complexidade da identidade LGBT Sem Terra, se dá pelas possibilidades dos eixos de opressão ao qual ela está exposta espacialmente.

\section{Relato de experiência da roda de conversa "Territorialização LGBT na luta pela terra no Brasil"}

A roda de conversa (Figura 1) se iniciou com o facilitador e pesquisador do PPGEO-UFU apresentando o tema da discussão que atualmente está efervescendo dentro dos movimentos de luta pela terra. Ele afirmou que seu professor no curso de Geografia e atual orientador, percebendo sua vontade de falar sobre gênero e sexualidade na academia, o indagou a pesquisar o tema, e que naquele momento a primeira coisa que pensou devido a sua vivência e concepção de gay da cidade foi: existe LGBT assumido no campo? Ao analisarmos o que levou a formulação dessa pergunta podemos constatar que há uma estrutura social que nos leva a ter a ideia de que o campo não é lugar para os LGBT, algo que foi se desconstruindo a partir do primeiro contato do facilitador com uma travesti líder de um assentamento rural durante o acampamento nacional do levante popular da juventude, em que pode perceber que 
os LGBT travam uma batalha imensa, pois além de lutarem pela terra, lutam para serem respeitados.

Figura 1 - Roda de conversa sobre a territorialização LGBT nos movimentos de luta pela terra

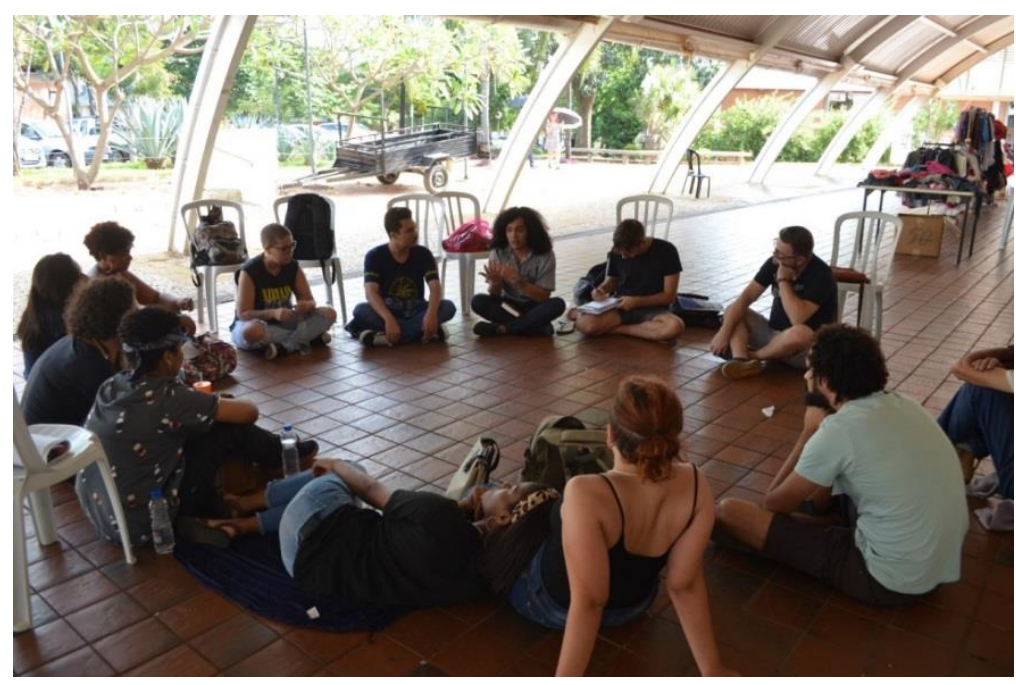

Fonte: SANTOS, S. L. S. G. (2019).

Logo após, o professor do Instituto de Geografia (IG) da UFU, e atual orientador do facilitador da roda, inicia sua fala dizendo que ao falarmos sobre territorialização LGBT nos movimentos de luta pela terra temos que compreender que falamos de territórios em disputa e que esse território está sendo construído de uma forma árdua. Ele ainda afirmou que falar de LGBT no campo, ainda mais na atual conjuntura brasileira, é uma posição política. No entanto, é necessário esclarecer também de qual campo estamos falando, pois apesar das questões de gênero nos movimentos de luta pela terra terem avançado bastante, ainda se percebe dificuldades, como por exemplo, a questão do lote e a produção ser do homem e os cuidados com os filhos e com a casa ser da mulher.

Posterior a essa explanação do tema houve um momento em que os facilitadores solicitaram que cada pessoa se apresentasse e que dissesse se já haviam tido contato com a temática. Nesse momento, constatamos que essa era uma temática nova para todos, mesmo alguns tendo contato com assuntos como agronegócio, MST etc.

Em meio à apresentação uma pergunta surgiu por parte de um integrante da roda: Como os movimentos sociais de luta pela terra lidam com a questão LGBT? O facilitador respondeu contando uma experiência que teve na escola Florestan Fernandes onde teve contato com um coletivo LGBT Sem Terra do MST e percebeu que o debate ainda ocorre de uma forma 
subversiva e não hegemônica dentro do próprio movimento, que, além de ser um movimento de luta pela terra é um movimento político e que, exatamente por isso, é bastante importante pautar gênero nos cursos de formação que esses movimentos oferecem.

Nesse instante, o professor reiterou que, quando se faz um recorte temporal da luta pela terra, observa-se que há sempre uma demanda principal que norteia os principais debates dentro dos movimentos. Na década de 1980, a luta dos sem-terra era propriamente pela terra, o que acarretou em uma organização que gerou acampamentos e assentamentos. Com o acesso das famílias à terra uma nova demanda chega: a educação, o que levou os movimentos a instalarem escolas dentro dos assentamentos. Logo após, surgiu a demanda das mulheres, que lutavam contra o patriarcado que se reproduziam dentro da sua casa, surgindo, assim, um setor de gênero dentro do MST. A inserção dos debates nos movimentos surge à luz do seu tempo. Urge, então, a necessidade de falar das temáticas LGBT que, até então, eram invisibilizadas nos movimentos de luta pela terra e na sociedade. Entretanto, ainda nos dias de hoje, temos o costume de achar que o rural não existe mais e que o LGBT existe somente no urbano. Nesse contexto, o indivíduo LGBT surge com um discurso que pauta a necessidade de reconhecimento de sua existência dentro dos movimentos e a conscientização dos outros militantes de que estão na mesma luta.

Uma estudante do curso de Geografia faz uma contribuição ao debate, dizendo que essa luta é invisibilizada em todos os âmbitos, como na mídia, na escola, e até mesmo na universidade, que deveria ser o principal local de debate por abrigar uma maior pluralidade de conhecimentos. O facilitador concorda com essa informação e afirma que acha bastante interessante como o Levante Popular da Juventude toca no assunto devido à frente camponesa que o movimento construiu, que propõe uma forma mais orgânica de trabalhar a temática LGBT. O facilitador continua sua fala dizendo que o LGBT no campo pede visibilidade (e não exclusividade) porque são sujeitos que foram invisibilizados durante anos. E exemplifica com uma experiência que teve ao conhecer um militante gay que havia mentido sobre sua sexualidade para conseguir ser assentado e que, com o surgimento do movimento LGBT dentro do MST, se encontrou dentro da luta pela terra.

Uma pergunta foi direcionada ao professor sobre a vivência dele no campo, sendo ele militante LGBT. Ele responde que desde que nasceu teve contato muito próximo com o conservadorismo, patriarcado e a religiosidade, o que afetou bastante sua vida. Naquele tempo, segundo ele, era muito mais difícil se aceitar e se entender porque não havia nenhuma 
referência, diferente de hoje. O professor conclui dizendo que, quando entrou na universidade e teve contato com debates de gênero e espacialidade, ele se encontrou, por isso é bastante importante ter espaços como essa roda de conversa dentro das universidades.

Uma doutoranda do PPGEO-UFU contribui para o debate, ressaltando a importância da roda de conversa e dizendo que essas conquistas não aparecem rapidamente, e que é necessário discutir sobre a questão LGBT e a emancipação da mulher na sociedade contemporânea para mudarmos o espaço onde vivemos.

\section{CONSIDERAÇÕES FINAIS}

O debate da diversidade sexual tem a sua agenda política situada no combate ao patriarcado. Este é o fundador da heteronormatividade, que nega a diversidade sexual e dificulta a reprodução da vida das pessoas LGBT. Esse processo se expressa comumente pelo discurso e está espacialmente localizado. Neste sentido, a Geografia se apresenta como uma possibilidade teórico-metodológica de compreensão das relações que circundam esse debate.

As LGBT Sem Terra têm arraigada em sua existência espacial uma complexa relação com a Geografia. A busca por território faz parte do cotidiano dos sujeitos da luta pela terra. As pessoas LGBT precisam, para além, estudar formas de resistir dentro do campo e ainda mais com as suas particularidades dentro dos movimentos da luta pela terra. Nesse sentido, há ainda muito a ser colocado para a inserção do movimento LGBT na luta pela terra.

Encerrando a roda, o facilitador afirmou que a luta LGBT é uma luta por direitos e que pensar na vivência LGBT no campo também é uma forma de pensar em direitos. Ele finaliza sua fala afirmando que, apesar de não haver consenso, é necessário falar sobre essa temática dentro dos movimentos de luta pela terra e na academia, e que é muito bom ver um espaço como esse de roda de conversa dentro de um evento tão importante na instituição.

\section{REFERÊNCIAS}

FERNANDES, B. M. Formação e territorialização do MST no Brasil: 1979-2005. In: ENCONTRO NACIONAL DE GEOGRAFIA AGRÁRIA - ENGA, 18., 2006., Rio de Janeiro. Anais [...], Rio de Janeiro, 2006. 
FERNANDES, B. M. Formação e territorialização do MST no Brasil. In: CARTER, M. Combatendo a desigualdade social: o MST e a reforma agrária no Brasil. São Paulo: Editora da Unesp, 2009. p. 161-198.

GERMER, C. Perspectivas das lutas sociais agrárias nos anos 90. In: STEDILE, J. P. et al. A questão agrária na década de 90. 4. ed. Porto Alegre: Editora da UFRGS, 2004. p. 259-284.

GOHN, M. G. História dos movimentos sociais: a construção da cidadania dos brasileiros, São Paulo: Loyola, 2001.

GRZYBOWSKI, C. Movimentos populares no Brasil: desafios e perspectivas. In: STEDILE, J. P. et al. A questão agrária na década de 90. 4. ed. Porto Alegre: Editora da UFRGS, 2004. p. 285-297.

IANNI, O. A formação do proletariado rural no Brasil. In: STEDILE, J. P. A questão agrária no Brasil: o debate de esquerda. 2. ed. São Paulo: Expressão Popular, 2005. p. 127-146.

LOERA N. R. Para além da barraca de lona preta: redes sociais e trocas em acampamentos e assentamentos do MST. In: FERNANDES, B. M.; MEDEIROS, L. S.; PAULILO, M. I. (org.). Lutas camponesas contemporâneas: condições, dilemas e conquistas. São Paulo: Editora da Unesp, 2009. p. 73-94.

MARIANO, A.; PAZ, T. T. Diversidade sexual e de gênero no MST: primeiros passos na luta pela liberdade sexual. In: NOGUEIRA, L. et al. Hasteemos a bandeira colorida: diversidade sexual e de gênero no Brasil. São Paulo: Expressão Popular, 2018. p. 289-314.

MARTINS, J. S. A militarização da questão agrária no Brasil. Vozes: Petrópolis, 1985.

MARTINS, J. S. O sujeito oculto: ordem e transgressão na reforma agrária. Porto Alegre: Editora da UFRGS, 2003.

MEDEIROS, L. S. História dos movimentos sociais no campo. Rio de Janeiro: Fase, 1989.

MOVIMENTO DOS TRABALHADORES RURAIS SEM TERRA (MST). Caderno de Formação $\mathbf{n}^{0}$ 5: diversidade sexual no MST: elementos para o debate. São Paulo: MST, Setor de Gênero, 2017.

PACHECO, M. E. L. O joio e o trigo na defesa da reforma agrária. In: STEDILE, J. P. et al. A questão agrária na década de 90. 4. ed. Porto Alegre: Editora da UFRGS, 2004. p. 203219.

PINTO, L. C. G. Reflexões sobre a política brasileira no período de 1964-1994. Revista da Associação Brasileira de Reforma Agrária, São Paulo, v. 25, n. 1, p.65-92, abr. 1995.

PORTO-GONÇALVES, C. W. Da geografia às geo-grafias: um mundo em busca de novas territorialidades. In: CECEÑA, A. E.; SADER, E. La guerra infinita hegemonia y terror mundial. Buenos Aires: CLACSO, 1997. p. 217-256.

RIBEIRO, L. N. Os territórios, a Via Campesina no Brasil e o conceito de movimento socioterritorial. Boletim do Dataluta, Presidente Prudente, v. 1, n. 2, p. 1-18, fev. 2015. 
SIGAUD, L. A engrenagem das ocupações de terra. In: FERNANDES, B. M.; MEDEIROS, L. S.; PAULILO, M. I. (org.). Lutas camponesas contemporâneas: condições, dilemas e conquistas. São Paulo: Editora da Unesp, 2009. p. 53-72.

STEDILE, J. P. Introdução. In: STEDILE, J. P. A questão agrária no Brasil: o debate de esquerda. 2. ed. São Paulo: Expressão Popular, 2005. p. 17-35.

VEIGA, J. E. O que é reforma agrária?: São Paulo: Abril Cultural; Brasiliense, 1984.

VIEIRA, F. B. Dos proletários unidos à globalização da esperança: um estudo sobre articulações internacionais de trabalhadores. 2008. 223 f. Tese (Doutorado em Planejamento Urbano e Regional) - Universidade Federal do Rio de Janeiro, Rio de Janeiro, 2008. 